\title{
Effect of Computational Constraints on Zero-Dimensional Computations for the Nanosecond-Order Ignition Process of the $\mathrm{CH}_{4}$ /Air Mixture
}

\author{
M. Suzuki ${ }^{a, b}$, Y. Morii ${ }^{a}$, H. Nakamura ${ }^{a}$, and K. Maruta ${ }^{a}$
}

UDC 544.45

Published in Fizika Goreniya i Vzryva, Vol. 57, No. 4, pp. 48-56, July-August, 2021.

Original article submitted June 10, 2020; revision submitted September 11, 2020; accepted for publication October 28, 2020.

\begin{abstract}
Zero-dimensional computations of nanosecond-order ignition using a nanosecond discharge are performed with two constraints. The effects of these constraints are assessed to study the experimental rapid pressure change properly at the initial stages. The computations are carried out with the following constraints: constant internal energy and volume (U\&V) and constant enthalpy and pressure $(\mathrm{H} \& \mathrm{P})$, revealing differences between the two solutions. As the pressure remains constant under the $\mathrm{H} \& \mathrm{P}$ constraint, the total number density of all species decreases during ignition. In this case, $\mathrm{O}$ radicals are less generated and consumed. The progression of all reactions and temperatures increases under the $\mathrm{H} \& \mathrm{P}$ constraint less intensely than under the $\mathrm{U} \& \mathrm{~V}$ constraint. Significant differences are found between the results calculated under the U\&V and $\mathrm{H} \& \mathrm{P}$ constraints. Therefore, large discrepancies with real phenomena can be caused if the loss due to pressure reduction is not treated well.
\end{abstract}

Keywords: nanosecond discharge, non-thermal plasma, non-equilibrium plasma, NRP discharge, plasma-assisted combustion, reactive compressive flow.

DOI: $10.1134 /$ S0010508221040055

\section{INTRODUCTION}

The fuel-lean burn technology for sparkignited (SI) reciprocating engines is beneficial for achieving high thermal efficiency because of the engines' high specific heat ratio and low burned gas temperature, which reduce the heat loss to the cylinder wall $[1,2]$. However, a lean burn shortcoming is the longer reaction time necessary because of lower laminar and turbulent burning velocities, which might engender an unstable reaction or extinction. To overcome this shortcoming, intense turbulence must be provided to increase the turbulent burning velocity. However, it is

\footnotetext{
${ }^{a}$ Institute of Fluid Science, Tohoku University, Sendai, 980-8577 Japan; m.suzuki@edyn.ifs.tohoku.ac.jp; labs@edyn.ifs.tohoku.ac.jp.

${ }^{b}$ Graduate School of Engineering, Tohoku University, Sendai, 980-8579, Japan.
}

widely known that ignition under intense turbulence under a lean fuel condition is extremely difficult because of the markedly increased need for the minimum ignition energy, i.e., so-called minimum ignition energy transitions [3-5]. Therefore, novel ignition technologies must be introduced to realize reliable lean burn engines.

In recent years, the non-equilibrium plasma has received increasing attention for improving ignition performance. There are two types of the plasma: thermal (equilibrium) and non-thermal (non-equilibrium) plasmas. The thermal plasma is characterized as having an electron temperature, with rotational and vibrational temperatures of particles. The electron and gas temperatures are in equilibrium at high temperatures. However, in the non-equilibrium plasma, the electron, vibrational, and rotational temperatures are extremely different. Only the electron temperature is higher than the gas temperature. When the non-equilibrium plasma 
is used for ignition, collisions of high-temperature electrons in the plasma generate active chemical species [6]. Reportedly, these active chemical species can enhance subsequent chain reactions and engender ignition with low energy. Several studies are progressing toward the introduction of the non-equilibrium plasma into an actual combustor, e.g., [7]. Nanosecond repetitively pulsed discharges (NRPDs) are known to be capable of creating the non-equilibrium plasma efficiently. Although the experimentally obtained results show that the NRPD improves the ignition process considerably, detailed mechanisms of the NRPD remain unclear [8] because the reaction processes that occur under the effects of the non-equilibrium plasma are complicated and the reactions occur in nanoseconds, which makes the experimental validation of the processes difficult. Therefore, it is expected that the numerical analysis plays an important role in elucidating the NRPD-induced ignition processes.

Mao and Chen [9] analyzed the ignition processes with the NRPD numerically. The ignition delay times of the premixed gas at the same temperature were compared between nanosecond discharges with different levels of the reduced electric field strength and ordinary auto-ignition. The results demonstrated that the ignition delay times are shorter than those of ordinary autoignition when the electric fields are applied sufficiently. The reports of other numerical studies described similar merits of the NRPD [10, 11].

Conventionally, the numerical analyses of ignition with the NRPD have been conducted assuming constant pressure conditions. Adamovich et al. [12] performed the numerical analyses assuming a constant pressure condition in a system using plate electrodes. In their study, the term representing the heat loss to the plate electrodes was incorporated into the zero-dimensional energy equation in the model. The numerical results showed good agreement with their experiments. In addition, Lefkowitz et al. [13, 14] conducted experiments using plate electrodes and a zero-dimensional analysis with the heat loss assuming a constant volume condition. The heat loss term proposed by Adamovich et al. [12] was applied to their model. The results of experiments conducted using plate electrodes were found to agree well with the numerical results found for a methane/oxygen mixture diluted with helium. The findings imply that consideration of the loss mechanism, including the heat loss to plate electrodes, in the numerical model is important for the numerical analyses.

Our group has started to undertake experimental efforts [15] using an NRPD with a pair of opposing rodtype sharpened electrodes for spark ignition engine applications. Conducting future multidimensional analy-

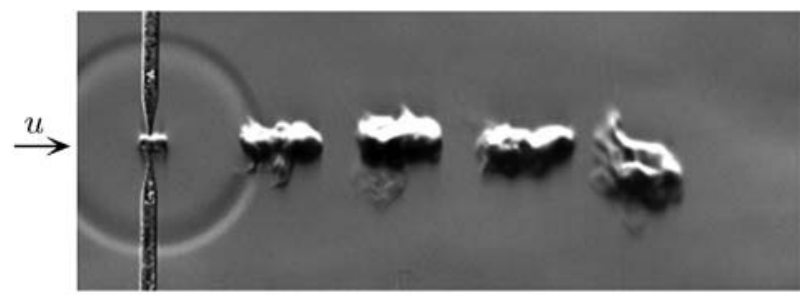

Fig. 1. Schlieren image of ignition kernel development $4 \mathrm{~ms}$ after the initial discharge pulse for the equivalence ratio of 0.6 , velocity of $10 \mathrm{~m} / \mathrm{s}$, gap distance of $2 \mathrm{~mm}$, and inter-pulse time of $1 \mathrm{~ms}$.

ses using rod-type sharpened electrodes is expected to require construction of a lower-dimensional model for consideration of the effects of pressure as a first trial because the pressure change has a markedly stronger effect than the heat loss as a loss mechanism for rod-type sharpened electrodes. During the ignition process, the pressure is varied by a high electric field that causes reactions lasting approximately for nanoseconds. For example, Fig. 1 presents a Schlieren image of the ignition kernel in the flow soon after the start of the fifth discharge observed by Lefkowitz and Ombrello [16], which is similar to the condition used in an earlier study [15]. As the figure shows, the shock wave propagates from the fifth discharge: a high-pressure region forms around the fifth discharge. This local high-pressure condition decreases immediately to the ambient pressure because of the rarefaction wave on the order of milliseconds. However, the pressure decrease takes longer than the nanosecond-order discharge. Therefore, the energy loss attributable to the pressure decrease on the order of nanoseconds is regarded as a plausible modeling strategy to consider the energy loss within the framework of a zero-dimensional model for a nanosecond discharge with rod-type sharpened electrodes. As an example, Fig. 2 presents schematic images showing the pressure increase or decrease during the discharge period. If the sharpened electrode diameters are set to $2 \mathrm{~mm}$, the rarefaction wave takes $1 \mu$ s or longer until it reaches the center axis of the electrode because the rarefaction wave propagation speed after the temperature rise can be assumed as $\approx 1000 \mathrm{~m} / \mathrm{s}$. The rarefaction wave propagates within about $0.1 \mathrm{~mm}$ from the electrode wall if one pulse of the discharge lasts for $100 \mathrm{~ns}$. Consequently, one can infer that a constant-volume and adiabatic system can be assumed until the rarefaction wave arrives. It is expected to be important to examine the effects of computational constraints by considering pressure change under such conditions. 
(a)
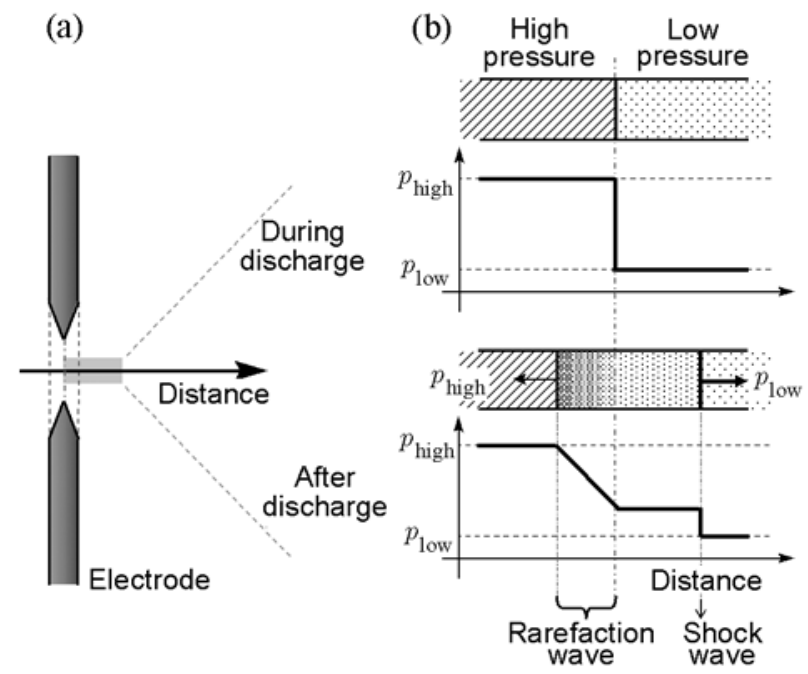

Fig. 2. Schematic images of the pressure increase/decrease during and after the discharge time: (b) pressure in the gray region between the electrodes shown in (a).

This study was conducted to obtain fundamental information from the analyses using different constraint conditions for a single nanosecond discharge. To address the realistic phenomena of the pressure change properly, we start the first trial from the examination of the effects of the constraint conditions with a zerodimensional computation. The commonly used constraints of two kinds are applied here: constant internal energy and volume (hereafter, $\mathrm{U} \& \mathrm{~V}$ ), for which the pressure is expected to reach the maximum theoretical values, and constant enthalpy and pressure (hereafter, $\mathrm{H} \& \mathrm{P}$ ), for which the pressure does not change. Special attention was devoted to differences in the ignition processes under the $\mathrm{U} \& \mathrm{~V}$ and $\mathrm{H} \& \mathrm{P}$ constraints.

\section{METHOD}

An in-house zero-dimensional ignition code and a zero-dimensional plasma kinetics solver (ZDPlasKin) [17] were used for examination of the ignition processes of a $\mathrm{CH}_{4} /$ air mixture initiated by a nanosecond discharge. The principle of the computational method is fundamentally the same as that reported by Lefkowitz et al. [13, 14]. The zero-dimensional governing equations are presented as

$$
\begin{gathered}
\frac{d Y_{k}}{d t}=\frac{\dot{\omega}_{k} W_{k}}{\rho}, \quad k=1, \ldots, K, \\
\dot{\omega}=\dot{\omega}_{\text {ZDPlasKin }}+\dot{\omega}_{c}, \\
\frac{d T}{d t}=-\frac{1}{\rho c} \sum_{k=1}^{K} \epsilon_{k} \dot{\omega}_{k} W_{k} .
\end{gathered}
$$

Here $\dot{\omega}\left[\mathrm{mol} /\left(\mathrm{m}^{3} \cdot \mathrm{s}\right)\right]$ is the production rate obtained by combining the species production rates of the plasma reaction $\dot{\omega}_{\text {ZDPlasKin }}$ and chemical reaction $\dot{\omega}_{c}$, $Y_{k}\left[\mathrm{~mol} / \mathrm{m}^{3}\right]$ stands for the mass fraction of the $k$ th species, $W_{k}[\mathrm{~kg} / \mathrm{mol}]$ represents the molecular weight of the $k$ th species, $T[\mathrm{~K}]$ is the temperature, $\rho\left[\mathrm{kg} / \mathrm{m}^{3}\right]$ is the density, $c[\mathrm{~J} /(\mathrm{kg} \cdot \mathrm{K})]$ expresses the specific heat at constant volume $\left(c_{v}\right)$ or constant pressure $\left(c_{p}\right)$, and $\epsilon_{k}[\mathrm{~J} / \mathrm{kg}]$ stands for the internal energy $u$ or enthalpy $h$ of the $k$ th species. The specific heat $c_{v}$ and energy $u$ were used under the $\mathrm{U} \& \mathrm{~V}$ constraint, and $c_{p}$ and $h$ were used under the $\mathrm{H} \& \mathrm{P}$ constraint.

The time integration of chemical and plasma reactions was performed using a fast and robust Jacobianfree time-integration method designated as MACKS developed by Morii and Shima [18]. The electron energy distribution function (EEDF) and the rate coefficients of the electron-impact reactions were found using a Boltzmann equation solver (BOLSIG+) [19] included in ZDPlasKin.

A stoichiometric $\mathrm{CH}_{4}$ /air mixture was used for this study. The initial conditions of the computation were set as $300 \mathrm{~K}$ ambient temperature and $0.1 \mathrm{MPa}$ pressure. The reduced electric field strength $(E / N[\mathrm{Td}])$ was calculated as

$$
\frac{E}{N}=T_{d} \sin \left(\pi \frac{t}{t_{p}}\right)
$$

where $E[\mathrm{~N} / \mathrm{C}]$ is the electric field strength, $N\left[\mathrm{~m}^{-3}\right]$ is the number of neutral particles in a unit volume, $T_{d}[\mathrm{Td}]$ stands for the maximum value of the electric field, and $t_{p}[\mathrm{~s}]$ represents the discharge time. For this study, $T_{d}=$ $160 \mathrm{Td}$ and $t_{p}=100 \mathrm{~ns}$ were applied in accordance with the relevant experimental conditions [15]. In addition, considering the ignition of highly turbulent fields, it was assumed that $T$ reaches a high value and the flame propagates under the U\&V constraint. Moreover, $E / N$ was calculated using Eq. (4) for the discharge time and set as zero for other times. It is noteworthy that computations for the single discharge were used here as a first trial to assess the pressure change effects in the nanosecond-order ignition processes.

\section{RESULTS AND DISCUSSION}

After presenting a discussion of the difference in the temperature rise between the $\mathrm{U} \& \mathrm{~V}$ and $\mathrm{H} \& \mathrm{P}$ constraints, the discussion in this section explains some factors producing differences. Attention will be devoted particularly to the chemical and plasma reactions that enhance ignition. Finally, we specifically examine the changes in the number density of all species caused by 


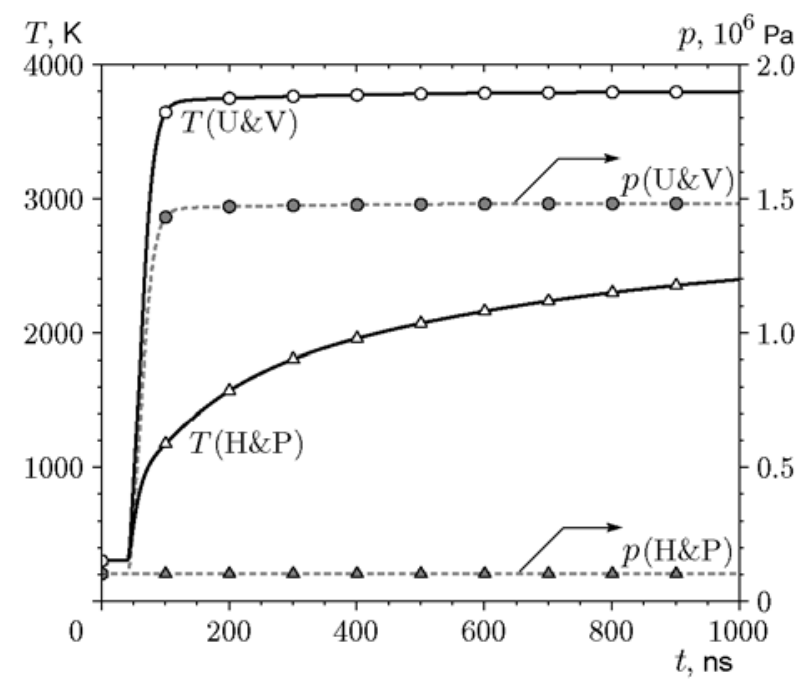

Fig. 3. Temperature and pressure histories as functions of time under the $\mathrm{U} \& \mathrm{~V}$ and $\mathrm{H} \& \mathrm{P}$ constraints: the symbols are shown for every 1000 data points.

the pressure change. An index for considering the energy loss because of decreased pressure will be examined from differences in the ignition processes under the $\mathrm{U} \& \mathrm{~V}$ and $\mathrm{H} \& \mathrm{P}$ conditions.

\subsection{Differences in Temperature and Pressure Histories under the $U \& V$ and $H \& P$ Constraints}

Figure 3 shows the temperature and pressure histories computed under the $\mathrm{U} \& \mathrm{~V}$ and $\mathrm{H} \& \mathrm{P}$ constraints. The reduced electric field strength $E / N$ in Eq. (4) is given in the period of $0-100$ ns. The maximum value $(160 \mathrm{Td})$ is reached at $50 \mathrm{~ns}$.

Under the $\mathrm{U} \& \mathrm{~V}$ constraint, the temperature increases rapidly during the discharge time $(<100 \mathrm{~ns})$ and becomes nearly constant $(3800 \mathrm{~K})$. Under the $\mathrm{H} \& \mathrm{P}$ constraint, however, the temperature increases gradually after its initial rapid rise to $\approx 1000 \mathrm{~K}$. Accordingly, for the discussion hereinafter, the present rapid temperature rise under the $\mathrm{U} \& \mathrm{~V}$ constrains is designates as "rapid ignition," and the slow temperature rise under the H\&P constraint is designated as "slow ignition." Indeed, for successful ignition by the NRPD in spark ignition engines, "rapid ignition" is necessary for maintaining reactions until the next discharge in highly turbulent fields. By contrast, "slow ignition" is observed under the $\mathrm{H} \& \mathrm{P}$ constrains, and it remains unclear at this stage whether ignition occurs before the next discharge.

A large difference was found in temperature rises between the $\mathrm{U} \& \mathrm{~V}$ and $\mathrm{H} \& \mathrm{P}$ conditions despite the same given values of the reduced electric field strength and



Fig. 4. Mole fractions of chemical species involved in typical methane reactions and number density of electrons under the U\&V (a) and H\&P (b) constraints: the symbols are shown for every 500 data points.

discharge time. Therefore, to investigate the differences in the ignition processes under the $\mathrm{U} \& \mathrm{~V}$ and $\mathrm{H} \& \mathrm{P}$ constraints, we discuss the mole fractions of electrons and some chemical species involved in typical methane reactions in the following sections.

\subsection{Mole Fractions of Electrons and Chemical Species Involved in Typical Methane Reactions}

Figure 4 shows the mole fractions of the major chemical species involved in typical methane reactions conventionally denoted by $\mathrm{C} 1$ and the number density of electrons under the $\mathrm{U} \& \mathrm{~V}$ and $\mathrm{H} \& \mathrm{P}$ constraints. The time period is $0-1 \mu \mathrm{s}$. The main reaction pathway of methane oxidation is known to be

$$
\mathrm{CH}_{4} \rightarrow \mathrm{CH}_{3} \rightarrow \mathrm{CH}_{2} \mathrm{O} \rightarrow \mathrm{HCO} \rightarrow \mathrm{CO} \rightarrow \mathrm{CO}_{2} \text {. }
$$


The major chemical species have the maximum values in the same sequence under both the $\mathrm{U} \& \mathrm{~V}$ and $\mathrm{H} \& \mathrm{P}$ conditions. Under the U\&V constraint, the number density of electrons increases rapidly during the discharge time. Other $\mathrm{C} 1$ reactions follow after the reactions of electrons. Finally, the mole fraction of the final product $\mathrm{CO}_{2}$ becomes nearly constant. Therefore, under the $\mathrm{U} \& \mathrm{~V}$ constraint, the $\mathrm{C} 1$ reactions can be regarded as completed within around $150 \mathrm{~ns}$ after the end of the discharge. However, under the $\mathrm{H} \& \mathrm{P}$ constraint, the number density of electrons and the mole fractions of other chemical species (except for $\mathrm{CO}$ ) are much smaller than those under the $\mathrm{U} \& \mathrm{~V}$ constraint. Moreover, the mole fractions of all chemical species continue to change after the end of the discharge. Therefore, chemical (C1) reactions are still in progress under the $\mathrm{H} \& \mathrm{P}$ constraint at $1 \mu \mathrm{s}$.

From the curves in Figs. 3 and 4, significant differences are found in the time histories of reactions conducted under the $\mathrm{H} \& \mathrm{P}$ and $\mathrm{U} \& \mathrm{~V}$ conditions. Under the $\mathrm{U} \& \mathrm{~V}$ constraint, "rapid ignition" caused by rapid $\mathrm{C} 1$ reactions is observed. However, "slow ignition" is observed under the $\mathrm{H} \& \mathrm{P}$ constraint, with $\mathrm{C} 1$ reactions remaining in progress.

Next, the rate of $\mathrm{O}$ radical production is specifically examined because it represents the largest amount among all neutral species generated by plasma reactions after the discharge. Earlier studies [20,21] showed that the $\mathrm{O}$ radical formation is accelerated by excited species generated by plasma reactions. In addition, $\mathrm{O}$ radicals are known as highly reactive. They contribute to the promotion of combustion reactions [22-24]. Herein, we distinguish O radical productions in "plasma reactions" and "chemical reactions" to capture the overall phenomena.

\subsection{Rate of $O$ Radical Production by Plasma and Chemical Reactions}

Among all neutral species, $\mathrm{O}$ radicals are present in the largest amounts because they are formed by thermal decomposition of $\mathrm{O}_{2}$ due to gas heating and plasma reactions involving excited species. The roles of excited $\mathrm{O}_{2}$ and active $\mathrm{O}$ radicals in the ignition processes were discussed not only in studies using the NRPD [6, 9, 13,22-24], but also in reports of studies of laser radiation [20] and electric discharge [21]. Accordingly, this section presents specific examination of the rate of $\mathrm{O}$ radical production. Figure 5 portrays the time history of the pressure and rate of $\mathrm{O}$ radical production in the period approximately from $35 \mathrm{~ns}$ (when the temperature increase starts) to $100 \mathrm{~ns}$ (when the discharge ends) for the U\&V and $\mathrm{H} \& \mathrm{P}$ conditions. The rates of $\mathrm{O}$ radical production computed by ZDPlasKin are shown

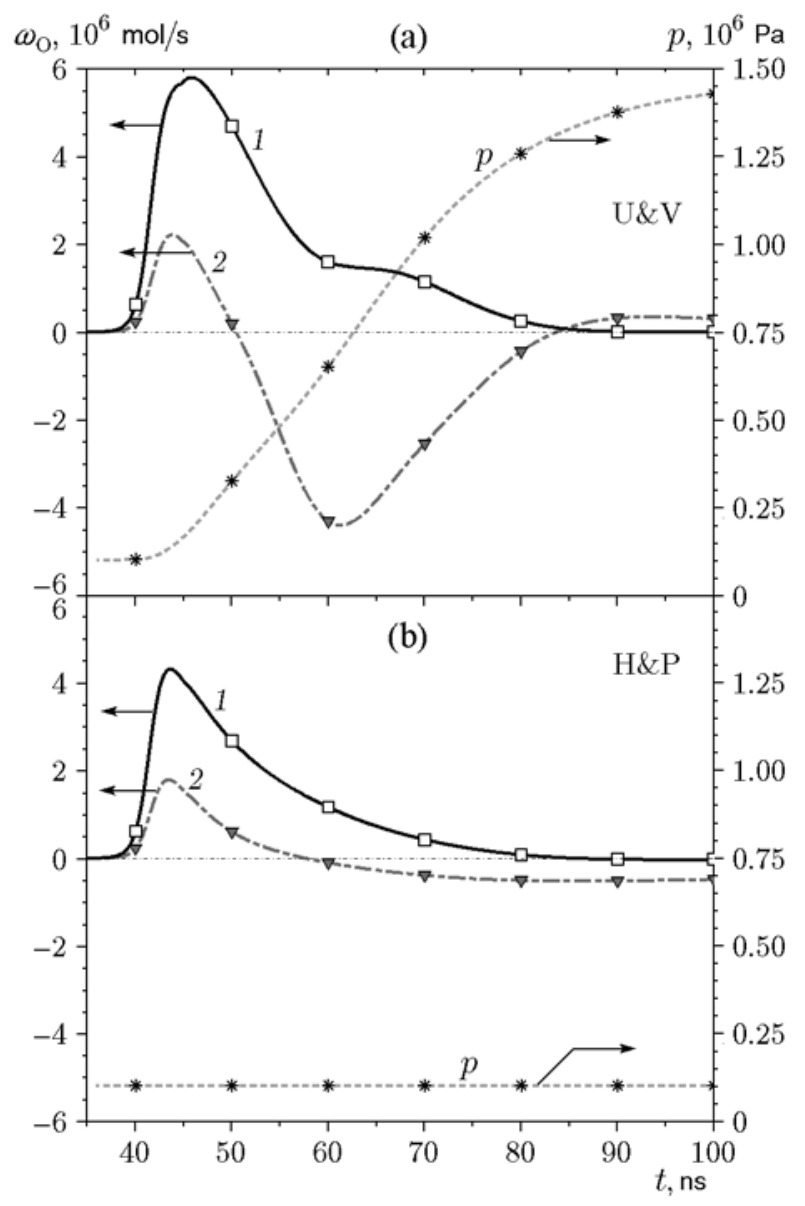

Fig. 5. Rate of $\mathrm{O}$ radical production under the U\&V constraint (a) and H\&P constraint (b): curves 1 and 2 refer to plasma reactions and chemical reactions, respectively; the symbols are shown for every 100 data points.

as "plasma reactions" (curves 1), and those predicted by the zero-dimensional ignition code are shown as "chemical reactions" (curves 2).

First, the results for the U\&V conditions are discussed (Fig. 5a). Both rates of production by "plasma reactions" and "chemical reactions" start increasing at around 40 ns along with the pressure. Particularly, the rate of $\mathrm{O}$ radical production by "plasma reactions" increases rapidly. However, the rate of production by "chemical reactions" reaches the maximum value at around 45 ns and becomes negative. $E / N$ reaches the maximum value at $50 \mathrm{~ns}$ (see Fig. 3). The results suggest that ignition can occur because $\mathrm{O}$ radicals generated by "plasma reactions" are consumed immediately in "chemical reactions": a transition from reactions induced by the plasma to reactions of combustion occurs. As a result, "rapid ignition" is observed under the U\&V constraint. 




Fig. 6. Mole fractions (squares) and number densities (asterisks) of $\mathrm{O}$ radicals and electronically excited species under the U\&V (a) and H\&P (b) constraints: the symbols are shown for every 10 points.

Under the H\&P constraint (Fig. 5b), however, the rates of both productions by "plasma reactions" and by "chemical reactions" increase as those under the U\&V constraint did, but the rate of production by "chemical reactions" does not decrease as it did under the $\mathrm{U} \& \mathrm{~V}$ constraint.

The rates of $\mathrm{O}$ radical production by "plasma reactions" and "chemical reactions" show different behaviors as the pressure increases under the U\&V constraint. In the following discussion, we specifically examine electronically excited species $\mathrm{N}_{2}(\mathrm{~A})$ and $\mathrm{N}_{2}(\mathrm{~B})$, which contribute to the generation of $\mathrm{O}$ radicals [9]. The time interval 35-60 ns, when "plasma reactions" are dominant under the U\&V constraint, will be specifically emphasized herein.

\author{
2.4. Mole Fraction \\ and Number Density of O Radicals \\ and Electronically Excited Species
}

Figure 6 presents the mole fractions and number densities of $\mathrm{O}$ radicals and electronically excited species $\mathrm{N}_{2}(\mathrm{~A})$ and $\mathrm{N}_{2}(\mathrm{~B})$ under the $\mathrm{U} \& \mathrm{~V}$ and $\mathrm{H} \& \mathrm{P}$ constraints.

First, we discuss the results for U\&V (Fig. 6a). An earlier study demonstrated that electronically excited species $\mathrm{N}_{2}(\mathrm{~A})$ and $\mathrm{N}_{2}(\mathrm{~B})$ contribute to the generation of $\mathrm{O}$ radicals [9]:

$$
\begin{aligned}
& \mathrm{N}_{2}(\mathrm{~A})+\mathrm{O}_{2} \rightarrow \mathrm{N}_{2}+2 \mathrm{O}, \\
& \mathrm{N}_{2}(\mathrm{~B})+\mathrm{O}_{2} \rightarrow \mathrm{N}_{2}+2 \mathrm{O} .
\end{aligned}
$$

The number density of $\mathrm{N}_{2}(\mathrm{~A})$ decreases greatly after 45 ns under the U\&V constraint. Therefore, the generation of $\mathrm{O}$ radicals is considered to be promoted by the reaction of oxygen and $\mathrm{N}_{2}(\mathrm{~A}, \mathrm{~B})$. In fact, the number of $\mathrm{O}$ radicals starts to decrease after $55 \mathrm{~ns}$, when the gas temperature reaches $1300 \mathrm{~K}$, because $\mathrm{O}$ radicals are consumed in combustion reactions. As described above, $\mathrm{O}$ radicals are highly reactive. Moreover, they promote combustion reactions. Therefore, because the reactions of combustion are enhanced considerably, "rapid ignition" is observed under the U\&V constraint. When $\mathrm{O}$ radicals are consumed in combustion reactions, it is considered that chemical reactions are shifted to a dominant state over non-equilibrium plasma reactions.

Next, the results for H\&P are discussed (Fig. 6b). The mole fractions and number densities increase rapidly and reach the maximum values. Although the maximum mole fractions are similar to those under the $\mathrm{U} \& \mathrm{~V}$ constraint, the maxima of the number densities are smaller than those in the U\&V case. The difference between the number densities becomes large after 50 ns. Particularly, a significant difference was found between the maximum number density and the mole fraction of $\mathrm{O}$ radicals. Under the $\mathrm{H} \& \mathrm{P}$ constraint, $\mathrm{O}$ radicals are not consumed as in the U\&V case. Consequently, reactions are not enhanced.

The tendency of the number densities is similar to those of the mole fractions under the $\mathrm{U} \& \mathrm{~V}$ constraint (see Fig. 6a). By contrast, different trends are observed under the H\&P constraint (see Fig. 6b). The mole fractions are calculated from the number density of each chemical species and the total number density of all chemical species. Therefore, we specifically examine the total number densities of all chemical species and pressures under the $\mathrm{U} \& \mathrm{~V}$ and $\mathrm{H} \& \mathrm{P}$ conditions. 


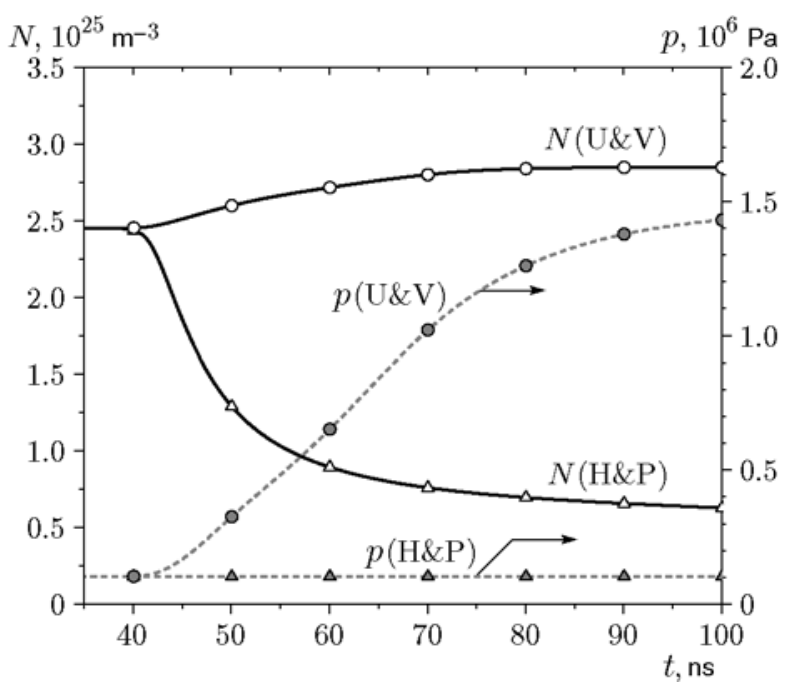

Fig. 7. Total number density of all chemical species and pressure change as a function of time under the $\mathrm{U} \& \mathrm{~V}$ and $\mathrm{H} \& \mathrm{P}$ constraints: the symbols are shown for every 10 data points.

\subsection{Total Number Density and Pressure Effects}

Figure 7 presents the total number density of all chemical species and pressure as a function of time under the $\mathrm{U} \& \mathrm{~V}$ and $\mathrm{H} \& \mathrm{P}$ constraints. Assuming the overall reaction of methane as

$$
\mathrm{CH}_{4}+2 \mathrm{O}_{2} \rightarrow \mathrm{CO}_{2}+2 \mathrm{H}_{2} \mathrm{O}
$$

the number density is expected not to lead to a marked change under the $\mathrm{U} \& \mathrm{~V}$ constraint because of the production of intermediates and the eventual convergence because equal amounts of substances must exist on the left and right sides of the overall chemical reaction formulae. As shown in Fig. 7, the total number density increases slightly because of radicals generated by the methane decomposition reaction. This slight increase can be regarded as reasonable under the $\mathrm{U} \& \mathrm{~V}$ constraint. However, to keep the pressure constant, the total number density decreases considerably under the $\mathrm{H} \& \mathrm{P}$ constraint. As the number density decreases, the number of reactions decreases because of the decreased rate of molecular collisions. This result might engender large discrepancies between the $\mathrm{H} \& \mathrm{P}$ results and actually observed phenomena.

In addition, under the $\mathrm{H} \& \mathrm{P}$ constraint, the decrease in the number density in Fig. 5 can be attributed to the fact that $\mathrm{O}$ radicals are not significantly generated or consumed, as they are in the U\&V case. As the density decreases under constant pressure conditions, the number density of electronically excited species that contribute to the generation of $\mathrm{O}$ radicals also decreases as the density decreases. Accordingly, the generation and consumption of $\mathrm{O}$ radicals are not promoted, which is also regarded as a possible reason why the combustion reaction was not accelerated under the $\mathrm{H} \& \mathrm{P}$ constraint, as might be readily apparent in Fig. 3 (temperature rise) and Fig. 4 (typical species in methane reactions). Consequently, "slow ignition" is observed because the reactions are not enhanced under the $\mathrm{H} \& \mathrm{P}$ constraint.

In summary, the following major problems were identified when the computations of nanosecond-order ignition using non-equilibrium plasma were conducted under the $\mathrm{H} \& \mathrm{P}$ assumption. Along with the reduced electric field strength $E / N$ in Eq. (4), the electric fields $E$ are inversely proportional to the number density of neutral molecules. However, the number density decreased considerably when the $\mathrm{H} \& \mathrm{P}$ constraint was assumed. The results obtained in this study under the $\mathrm{H} \& \mathrm{P}$ constraint were inconsistent with actual phenomena. Therefore, the constraints should be chosen carefully for the case of rapid ignition using the NRPD. Based on this point, we are planning to compute the ignition process with incorporation of spatial dimensions in future studies.

\section{CONCLUSIONS}

Zero-dimensional computations of nanosecondorder ignition processes of $\mathrm{CH}_{4}$ /air mixtures were performed using the NRPD under constraints of two types: constant internal energy and volume (U\&V) and constant enthalpy and pressure $(\mathrm{H} \& \mathrm{P})$. Particular attention was devoted to the differences in the ignition processes under the $\mathrm{U} \& \mathrm{~V}$ and $\mathrm{H} \& \mathrm{P}$ constraints. The results show that a significant difference exists in temperature rises despite the initially equal values of the reduced electric field strength and given discharge times. As the pressure changes were considered under the U\&V condition, the total number density increased slightly because radicals were generated by the $\mathrm{CH}_{4}$ decomposition reaction. The $\mathrm{O}$ radicals were generated efficiently by plasma-induced species and were consumed in combustion reactions under the $\mathrm{U} \& \mathrm{~V}$ constraint. Consequently, "rapid ignition" was observed in the U\&V case. However, as the pressure is kept constant under the $\mathrm{H} \& \mathrm{P}$ constraint, the total number density decreased considerably. Accordingly, $\mathrm{O}$ radicals were not significantly generated and consumed in the H\&P case as they were under the U\&V constraint, which might engender large discrepancies with actual phenomena. In conclusion, one must assume appropriate conditions when performing computations for nanosecond-order ignition using 
the NRPD. For future studies, we will conduct a spatially one-dimensional analysis to investigate the ignition process.

The authors sincerely thank Dr. Xingqian Mao from the Beijing Jiaotong University of China for providing chemical and non-equilibrium plasma reaction mechanisms. Part of this work was supported by the Automotive Internal Combustion Engine Technology Research Association (AICE).

\section{OPEN ACCESS}

This article is licensed under a Creative Commons Attribution 4.0 International License, which permits use, sharing, adaptation, distribution and reproduction in any medium or format, as long as you give appropriate credit to the original author(s) and the source, provide a link to the Creative Commons license, and indicate if changes were made. The images or other third party material in this article are included in the article's Creative Commons license, unless indicated otherwise in a credit line to the material. If material is not included in the article's Creative Commons license and your intended use is not permitted by statutory regulation or exceeds the permitted use, you will need to obtain permission directly from the copyright holder. To view a copy of this license, visit http://creativecommons.Org/licenses/by/4.0/.

\section{REFERENCES}

1. Strategic Innovation Promotion Program, Innovative Combustion (Japan Science and Technology Agency); http:// www.jst.go.jp/sip/k01.html.

2. K. Nakata, S. Nogawa, D. Takahashi, et al., "Engine Technologies for Achieving 45\% Thermal Efficiency of S. I. Engine," SAE Int. J. Engines 9 (1), 179-192 (2016); DOI: https://doi.org/10.4271/2015-01-1896.

3. C. C. Huang, S. S. Shy, C. C. Liu, and Y. Y. Yan, "A Transition on Minimum Ignition Energy for Lean Turbulent Methane Combustion in Flamelet and Distributed Regimes," Proc. Combust. Inst. 31 (1), 1401-1409 (2007); DOI: https://doi.org/10.1016/j.proci.2006.08.024.

4. K. Maruta and H. Nakamura, "Super Lean-Burn in SI Engine and Fundamental Combustion Studies," J. Combust. Soc. Jpn. 58 (183), 9-19 (2016); DOI: https://doi.org/10.20619/jcombsj.58.183_9.

5. L. J. Jiang, S. Q. Shy (Steven), M. T. Nguyen, et al., "Spark Ignition Probability and Minimum Ignition Energy Transition of the Lean IsoOctane/Air Mixture in Premixed Turbulent Combus- tion," Combust. Flame 187, 87-95 (2018); DOI: https://doi.org/10.1016/j.combustflame.2017.09.006.

6. I. N. Kosarev, N. L. Aleksandrov, S. V. Kindysheva, et al., "Kinetics of Ignition of Saturated Hydrocarbons by Nonequilibrium Plasma: $\mathrm{C}_{2} \mathrm{H}_{6} 6^{-}$to $\mathrm{C}_{5} \mathrm{H}_{12}$-Containing Mixtures," Combust. Flame 156 (1), 221-233 (2009); DOI: https://doi.org/10.1016/j.combustflame.2008.07.013.

7. Y. Ju and W. Sun, "Plasma Assisted Combustion: Dynamics and Chemistry," Prog. Energy Combust. Sci. 48, 21-83 (2015); DOI: https:// doi.org/10.1016/j.pecs.2014.12.002.

8. A. Yu. Starikovskii, "Plasma Supported Combustion," Proc. Combust. Inst. 30 (2), 2405-2417 (2005); DOI: https://doi.org/10.1016/j.proci.2004.08.272.

9. X. Mao and Q. Chen, "Effects of Vibrational Excitation on Nanosecond Discharge Enhanced Methane-Air Ignition," AIAA J. 56 (11), 4312-4320 (2018); DOI: https://doi.org/10.2514/1.j057304.

10. S. A. Bozhenkov, S. M. Starikovskaia, and A. Yu. Starikovskii, "Nanosecond Gas Discharge Ignition of $\mathrm{H}_{2}$ and $\mathrm{CH}_{4}$ Containing Mixtures," Combust. Flame 133 (1/2), 133-146 (2003); DOI: https://doi.org/10.1016/S0010-2180(02)00564-3.

11. S. M. Starikovskaia, "Plasma Assisted Ignition and Combustion," J. Phys. D. Appl. Phys. 39 (16), R265R299 (2006); DOI: https:// doi.org/10.1088/0022$3727 / 39 / 16 / \mathrm{R} 01$.

12. I. V. Adamovich, M. Nishihara, I. Choi, et al., "Energy Coupling to the Plasma in Repetitive Nanosecond Pulse Discharges," Phys. Plasmas 16 (11), 113505(1-13) (2009); DOI: https://doi.org/10.1063/1.3264740.

13. J. K. Lefkowitz, P. Guo, A. Rousso, and Y. Ju, "Species and Temperature Measurements of Methane Oxidation in a Nanosecond Repetitively Pulsed Discharge," Phil. Trans. Roy. Soc. A. Math. Phys. Eng. Sci. 373 (2048), 1-21 (2015); DOI: https://doi.org/10.1098/rsta.2014.0333.

14. J. K. Lefkowitz, P. Guo, A. Rousso, and Y. Ju, "Low Temperature Oxidation of Methane in a Nanosecond Pulsed Plasma Discharge," in 53rd AIAA Aerospace Sciences Meeting, 2015, pp. 1-12; DOI: https://doi.org/10.2514/6.2015-0665.

15. K. Uesugi, Y. Morii, T. Mukoyama, et al., "Ignition Experiments by Nanosecond Repetitively Pulsed Discharges in Intense Turbulence for Ssuper Lean Burn at Engine Condition," in 2019 JSAE/SAE Powertrains, Fuels Lubricans International Meeting, (Kyoto, Japan, 2019), JSAE20199308/SAE2019-01-2160; DOI: https://doi.org/10.4271/2019-01-2160.

16. J. K. Lefkowitz and T. Ombrello, "An Exploration of Inter-Pulse Coupling in Nanosecond Pulsed High Frequency Discharge Ignition," Combust. Flame 180, 136-147 (2017); DOI: https://doi.org/10.1016/j.combustflame.2017.02.032. 
17. S. Pancheshnyi, B. Eismann, G. J. M. Hagelaar, and L. C. Pitchford, "Computer Code ZDPlasKin, Ver. 2.0," LAPLACE, CNRS-UPS-INP (Univ. of Toulouse, France, 2008); http://www.zdplaskin.laplace.univtlse.fr.

18. Y. Morii and E. Shima, "Optimization of OneParameter Family of Integration Formulae for Solving Stiff Chemical-Kinetic ODEs," Scientific Reports 10, 21330 (2020); DOI: https://doi.org/10.1038/s41598020-78301-6.

19. G. J. M. Hagelaar and L. C. Pitchford, "Solving the Boltzmann Equation to Obtain Electron Transport Coefficients and Rate Coefficients for Fluid Models," Plasma Sources Sci. Technol. 14 (4), 722-733 (2005); https://doi.org/10.1088/0963-0252/14/4/011.

20. A. M. Starik and N. S. Titova, "Possibility of Initiation of Combustion of $\mathrm{CH}_{4}-\mathrm{O}_{2}$ (Air) Mixtures with LaserInduced Excitation of $\mathrm{O}_{2}$ Molecules," Fiz. Goreniya Vzryva 40 (5), 3-15 (2004) [Combust., Expl., Shock Waves 40 (5), 499-510 (2004)].
21. A. M. Starik, B. I. Lukhovitskii, and N. S. Titova, "Initiation of Combustion of a $\mathrm{CH}_{4}-\mathrm{O}_{2}$ Mixture in a Supersonic Flow with Excitation of $\mathrm{O}_{2}$ Molecules by an Electric Discharge," Fiz. Goreniya Vzryva 44 (3), 3-16 (2008) [Combust., Expl., Shock Waves 44 (3), 249-261 (2008)].

22. S. Starikovskaia et al., "Analysis of Ignition by Nonequilibrium Sources. Ignition of Homological Series of Hydrocarbons by Volume Nanosecond Discharge," in 44th AIAA Aerospace Sci. Meeting Exhibit (Nevada, 2006), pp. 1-14; https://doi.org/10.2514/6.2006-616.

23. W. Sun, "Non-Equilibrium Plasma-Assisted Combustion," Ph.D. Thesis (Dep. of Mech. and Aerosp. Eng., Princeton Univ., 2013); http://arks.princeton. edu/ark:/88435/dsp01pn89d663g.

24. X. Mao, A. Rousso, Q. Chen, and Y, Ju, "Numerical Modeling of Ignition Enhancement of $\mathrm{CH}_{4} / \mathrm{O}_{2} / \mathrm{He}$ Mixtures using a Hybrid Repetitive Nanosecond and DC Discharge," Proc. Combust. Inst. 37 (4), 5545-5552 (2019); DOI: https:// doi.org/10.1016/j.proci.2018.05.106. 